\title{
BMJ Open Investigating the relationship between precocious puberty and obesity: a cross- sectional study in Shanghai, China
}

\author{
Chang Chen, ${ }^{1,2}$ Yunting Zhang, ${ }^{3,4}$ Wanqi Sun, ${ }^{5}$ Yao Chen, ${ }^{4,6}$ Yanrui Jiang, ${ }^{5}$ \\ Yuanjin Song, ${ }^{5}$ Qinmin Lin, ${ }^{5}$ Lixia Zhu, ${ }^{5}$ Qi Zhu, ${ }^{5}$ Xiumin Wang, ${ }^{6}$ Shijian Liu, ${ }^{1,2}$ \\ Fan Jiang ${ }^{4,5}$
}

To cite: Chen C, Zhang Y, Sun W, et al. Investigating the relationship between precocious puberty and obesity: a cross-sectional study in Shanghai, China. BMJ Open 2017;7:e014004. doi:10.1136/ bmjopen-2016-014004

- Prepublication history and additional material is available. To view please visit the journal (http://dx.doi.org/10.1136/ bmjopen-2016-014004).

Received 24 August 2016 Revised 9 March 2017 Accepted 13 March 2017

CrossMark

For numbered affiliations see end of article.

\section{Correspondence to}

Dr Shijian Liu; liushijian@scmc.com.cn and Fan Jiang;

fanjiang@shsmu.edu.cn

\section{ABSTRACT}

Objectives Obesity is reported to be closely relevant to early sexual development but the relationship between sexual precocity and obesity or central obesity is still inconsistent, especially in boys. We aimed to investigate the relationship between precocious puberty and obesity as well as central obesity.

Design A large population-based cross-sectional study using multistage, stratified cluster random sampling.

Setting Data from the Shanghai Children's Health, Education and Lifestyle Evaluation (SCHEDULE) study in June 2014.

Participants 17620 Chinese children aged 6-12 years. Primary and secondary outcome measures Obesity was defined by WHO Child Growth Standards. Central obesity was defined by sex-specific waist-to-height ratio (WHtR) cut-offs (WHtR $\geq 0.48$ for boys, WHtR $\geq 0.46$ for girls). Precocious puberty was identified by Tanner stage of breast, pubic hair and testicle development. $\mathrm{A} \chi^{2}$ test was performed to compare rates. Odds ratios (ORs) with 95\% confidence intervals (Cls) were calculated to assess the association between precocious puberty and general obesity and central obesity. Probit analysis was used for estimating the median age at entry into Tanner stage 2 or greater for breast, pubic hair and testicle development. Linear regression was utilised to compare the effects of WHtR and body mass index (BMI) on sex development indicators.

Results $25.98 \%$ and $38.58 \%$ of boys with precocious puberty were respectively accompanied by obesity $(0 \mathrm{R}=2.15,95 \% \mathrm{Cl}=1.31$ to 3.50$)$ or central obesity $(\mathrm{OR}=2.10,95 \% \mathrm{Cl}=1.46$ to 3.03$)$; meanwhile, $13.86 \%$ and $29.42 \%$ of girls with precocious puberty were respectively accompanied by obesity $(\mathrm{OR}=9.00,95 \% \mathrm{Cl}=5.60$ to 14.46$)$ or central obesity $(\mathrm{OR}=5.40,95 \% \mathrm{Cl}=4.10$ to 7.12$)$. The median ages of breast, pubic hair and testicle development decreased with BMI increase and median ages of thelarche and testicular development rather than pubarche were earlier in children with central obesity.

Conclusions Earlier pubertal development was positively associated with obesity and central obesity in Chinese children.

\section{INTRODUCTION}

Puberty is an essential and complex process with wide physiological variation and maturation.

\section{Strengths and limitations of this study}

This study is a large population-based crosssectional study and the subjects were representative of the general population in Shanghai.

- Early pubertal development was found to be associated with obesity and central obesity which is of relevance to the current public health concern about the risk factors associated with the earlier onset of puberty.

- Longitudinal investigations are still needed to determine the causal association between obesity and precocious puberty.

- Imaging diagnosis of breast and testicle development such as B-ultrasonic scan may help to reduce false positives in future research.

Mechanisms controlling the onset of puberty and tempo of development are complicated and involve genetic, nutritional and environmental interactions. ${ }^{1}$ Increasing numbers of countries are experiencing earlier development of secondary sexual characteristics in children. ${ }^{2-4}$ Earlier puberty has been reported to be associated with a higher risk of psychological problems, reproductive tract cancers and the development of metabolic syndrome features later in life. ${ }^{5}$

Recent data suggest that earlier timing or faster progression of pubertal development is related to higher body mass index (BMI) and greater risk of overweight in later adolescence and adulthood. ${ }^{6}$ Those who develop earlier tend to be more obese, with a trunk-oriented distribution pattern from adolescence to adulthood. ${ }^{8}$ Also, children with overweight and obesity appear to sexually develop earlier than lean children. ${ }^{9}$ The underlying biological mechanisms like insulin resistance with compensatory hyperinsulinaemia, endocrine disruptors and androgens in girls may contribute to the sexual characteristic changes. ${ }^{10}$ In addition, a central or abdominal distribution of body fat was reported to 


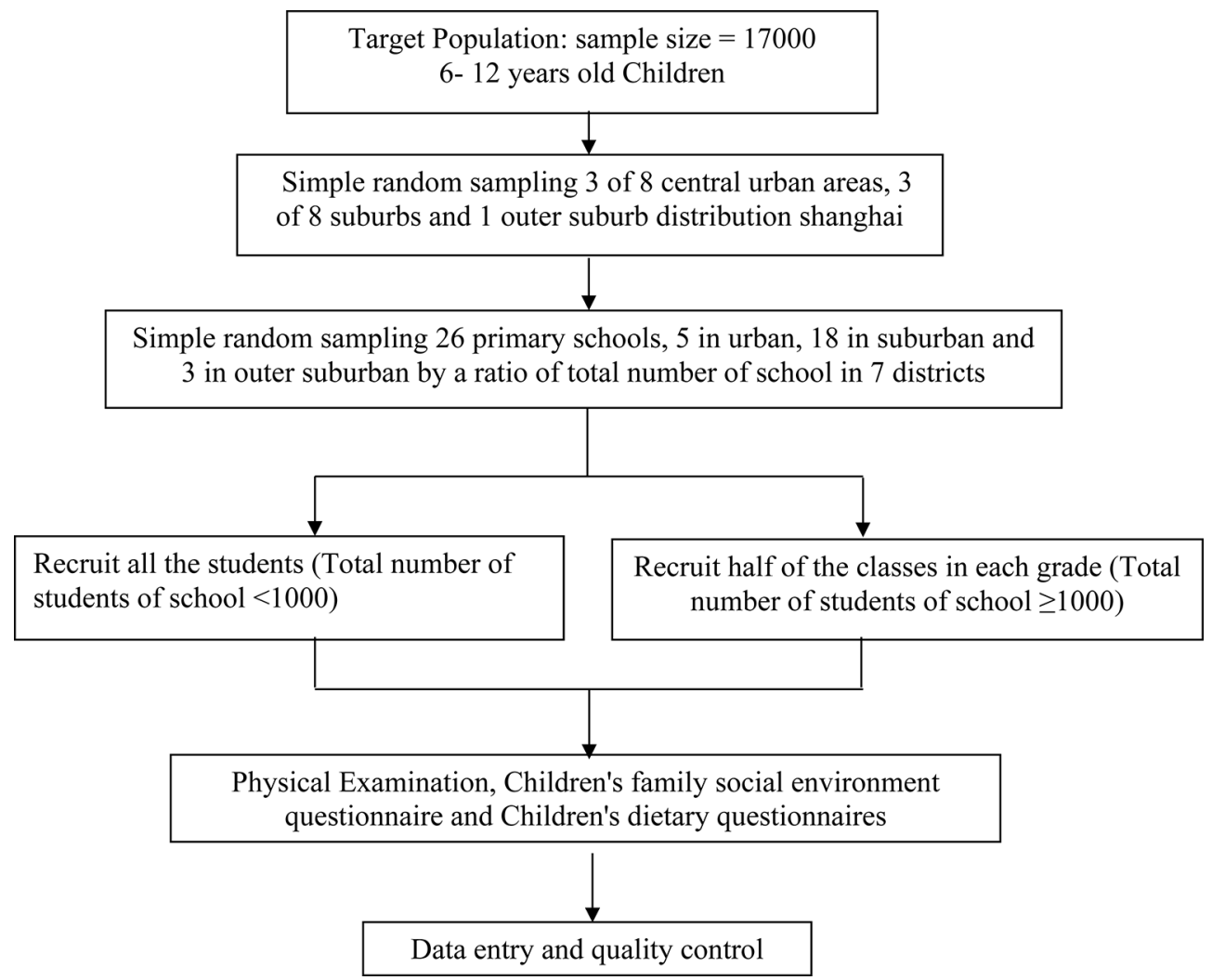

Figure 1 Sampling theme of the study. This study was conducted by multistage and stratified cluster random sampling. Seven districts were randomly chosen, 26 general primary schools were randomly sampled.

be related to adverse health outcomes compared with peripheral fat, which implied body fat patterning may also influence sexual maturation. ${ }^{71}$

The relationship between sexual precocity and obesity or central obesity is still inconsistent, especially in boys. The purpose of this study is to evaluate the relationship between the timing of sexual maturation and body mass, as well as the effect of central obesity on precocious puberty.

\section{METHODS}

\section{Participants and sampling}

Informed consent was obtained from the participant children and their parents and the study was approved by the Institutional Review Boards of the Shanghai Children's Medical Centre. The participants were selected from the Shanghai Children's Health, Education and Lifestyle Evaluation (SCHEDULE) study. This cross-sectional study was conducted in June 2014 by multistage and stratified cluster random sampling. Nineteen districts of Shanghai were stratified into central urban area, suburb and outer suburb according to the 2005 Shanghai census report ${ }^{12}$ and seven districts were randomly chosen, including Jing'an, Changning, Zhabei, Jiading, Jinshan, Pudong and Chongming. From these, 26 general primary schools were randomly sampled from school lists and students in grades 1-5 were recruited (figure 1). Children who had been diagnosed with organic disease (such as ovarian tumour, hamartoma, etc.), chronic diseases (such as chronic kidney disease, asthma, epilepsy, etc.), genital abnormalities (such as cryptorchidism, hypospadias, etc.), and children receiving medication (such as glucocorticoid) which could cause precocious puberty were excluded from the study. Trained teachers handed out questionnaires to the recruited students, asking them to take the questionnaires home and requesting that their parents complete the questionnaires concerning family, social and environmental issues as well as dietary habits. Then teachers collected the completed questionnaires and returned them to the investigators. Data were analysed in 2016.

\section{Physical examination}

Sexual development of children was jointly evaluated by professional paediatric endocrinology physicians and paediatric care physicians. The pubertal assessments of breast development used inspection combined with palpation. For girls with obesity, close attention was paid to the palpation of nodules in the breast. In boys, testicular volume was determined by palpation and a testicular metre; that is, testicles were palpated and compared with the most similar bead on an orchidometer. The Tanner staging method was adopted to assess sexual development in children. The pubertal stages of breast and pubic hair development were graded from 1 (prepubertal) to 5 (fully mature) and delineated by Marshall and Tanner. ${ }^{1314}$ Precocious puberty was considered as being under 8 years 
for Tanner stage 2 or above for breast $\left(\mathrm{B}_{2}\right)$ or pubic hair development $\left(\mathrm{PH}_{2}\right), 10$ years for menstruation in girls, and under 9 years for Tanner stage 2 or above for pubic hair or testicle development $\left(\mathrm{T}_{2}\right)$ (testicular volume, $\mathrm{TV} \geq 4 \mathrm{~mL}$ ) in boys. ${ }^{15-17}$

Height measurement to the nearest $0.1 \mathrm{~cm}$ was performed without shoes and standing upright by a wallmounted stadiometer. Participants wore light clothes and were barefoot when weight was measured by research assistants using a standardised digital scale to the nearest $0.1 \mathrm{~kg}$. Waist circumference (WC) was obtained to the nearest $0.1 \mathrm{~cm}$ with an inelastic measuring tape at the midpoint of the horizontal line between the lower rib margin and the superior iliac border while the participant was standing and at the end of normal expiration. Calculation of BMI was weight $(\mathrm{kg})$ divided by the square of height $\left(\mathrm{m}^{2}\right)$. Subjects were classified into severe thinness, thinness, overweight and obesity categories according to the WHO Child Growth Standards (http://www.who. int/growthref/en/); that is, severe thinness is $\mathrm{BMI}<-3$ $\mathrm{SD}$, thinness is $\mathrm{BMI}<-2 \mathrm{SD}$, overweight is $\mathrm{BMI} \geq 1 \mathrm{SD}$ and obesity is $\mathrm{BMI} \geq 2 \mathrm{SD} .{ }^{1819}$ The overweight category excludes obesity and thinness excludes severe thinness. BMI was converted to BMI Z-scores based on the mean and the SD of the children in the same age group and of the same gender. Waist-to-height ratio (WHtR) was calculated as WC $(\mathrm{cm})$ divided by height $(\mathrm{cm})$ and central obesity was defined as $\mathrm{WHtR} \geq 0.48$ in boys and $\mathrm{WHtR} \geq 0.46$ in girls. ${ }^{20}$ All physical data were collected in school settings.

\section{Statistical analysis}

All data were recorded and proofread using EpiData 3.1 (EpiData Association, Odense, Denmark) by two groups of researchers. The detection rate of precocious puberty was directly calculated and the $\chi^{2}$ test was performed to compare rates. Odds rations (ORs) with $95 \%$ confidence intervals (CIs) were calculated to assess the association between precocious puberty, general obesity and central obesity. Probit analysis was used for estimating the median age of the population at entry into Tanner stage 2 or greater for breast, pubic hair and testicular development. Linear regression was applied to evaluate the relationship between WHtR, BMI Z-score and sexual maturation among children with Tanner stage 2 breast, pubic hair or testicle development. All the raw data were analysed using IBM SPSS Statistic package version 21 (IBM Corp., Armonk, New York, USA), two sided, and $\mathrm{p}$ value $<0.05$ was considered statistically significant.

\section{RESULTS}

\section{Sample}

A total of 17620 parents of recruited children completed the questionnaires, and $17368(98.57 \%)$ were valid. The number of 6-12-year-old children who completed the physical examination was 16958 (96.24\%). After eliminating missing (845), extreme and invalid data (176) for age, gender and key physical parameters including height and weight, a total of $15937(90.45 \%)$ children constituted the final sample, including $8546(53.62 \%)$ boys and $7391(46.38 \%)$ girls with an age range from 6 to 12 years.

\section{Subject characteristics}

Boys had obviously higher levels of weight, height, WC (7 missing), BMI and WHtR than girls $(\mathrm{p}<0.005)$. Moreover, the prevalence of both obesity and central obesity was relative higher in boys than girls (the prevalence of obesity was $18.61 \%$ for boys and $5.63 \%$ for girls; central obesity was $28.65 \%$ for boys and $13.09 \%$ for girls) $(\mathrm{p}<0.001)$. A total of 4221 boys aged $6-9$ years, 2000 girls aged $6-8$ years and girls with menstruation aged below 10 years were diagnosed with or without precocious puberty according to the age-specific definition. The overall detection rate of precocious puberty of boys was $9.53 \%$ (596 cases). Girls (469 cases, $23.07 \%$ ) had a significantly higher rate than boys $(127$ cases, $3.01 \%)(\mathrm{p}<0.001)$. (table 1$)$

Relationship between different types of obesity and the risk of precocious puberty

The prevalence of obesity and central obesity was relatively high and had an obvious influence on precocious puberty in both genders. table 2 shows the results. A total of $25.98 \%$ of boys with precocious puberty and $13.86 \%$ of girls with precocious puberty had obesity. Childhood obesity increased the risk of precocious puberty and the risk was obviously higher in girls than boys (boys: $\mathrm{OR}=2.15$, 95\% $\mathrm{CI}=1.31$ to 3.5 ; girls: $\mathrm{OR}=9.00,95 \% \mathrm{CI}=5.60$ to 14.46 ). Moreover, $38.58 \%$ of boys with precocious puberty and $29.42 \%$ of girls with precocious puberty had central obesity. Central obesity had a relatively similar effect on obesity (boys: $\mathrm{OR}=2.10,95 \% \mathrm{CI}=1.46$ to 3.03 ; girls: $\mathrm{OR}=5.40,95 \% \mathrm{CI}=4.10$ to 7.12 ). The status of obesity using either BMI or WHtR was significantly associated with precocious puberty.

\section{Attaining median age of pubertal stages}

We estimated the median age of both girls and boys and the $95 \%$ CIs for attainment of Tanner stage 2 for breast, pubic hair and testicle development according to probit analysis (table 3).

For girls, the median age of $B_{2}$ was 10.86 in the severe thinness group, 9.88 in the thinness group, 8.85 in the normal weight group, 7.68 in the overweight group and 7.14 in the obesity group. The same decreasing trend with increasing BMI was observed in the median ages of $\mathrm{PH}_{2}: 12.56,11.13,10.73,10.22$ and 10.18 years. For boys, median ages of $\mathrm{PH}_{2}$ and $\mathrm{T}_{2}$ decreased slightly with increasing BMI, except for a lower median age of $\mathrm{PH}_{2}$ in the severe thinness group. The median ages of $\mathrm{B}_{2}, \mathrm{PH}_{2}$ and $\mathrm{T}_{2}$ showed a negative association with BMI. This demonstrated a significant downward trend in median age of thelarche, pubarche and testicular development with an increase in BMI in 6-12-year-old children.

For girls, the median ages of $\mathrm{B}_{2}$ and $\mathrm{PH}_{2}$ were 8.69 $(95 \% \mathrm{CI}=8.64$ to 8.74$)$ and $10.62(95 \% \mathrm{CI}=10.53$ to 10.72$)$ years for those with non-central obesity, and $7.20(95 \%$ 
Table 1 Basic characteristics of the subjects

\begin{tabular}{|c|c|c|c|c|c|}
\hline & Total & Boys & Girls & & \\
\hline Variables & $\mathrm{n}=15937$ & $\mathrm{n}=8546$ & $n=7391$ & $\chi^{2} / \mathrm{t}$ & p value ${ }^{*}$ \\
\hline Age (years) & & & & 5.54 & 0.354 \\
\hline 6 & $856(5.37)$ & $469(5.49)$ & $387(5.24)$ & & \\
\hline 7 & $3549(22.27)$ & $1936(22.65)$ & $1613(21.82)$ & & \\
\hline 8 & 3341 (20.96) & $1816(21.25)$ & 1525 (20.63) & & \\
\hline 9 & $3318(20.82)$ & $1731(20.26)$ & $1587(21.47)$ & & \\
\hline 10 & $2758(17.31)$ & $1467(17.17)$ & $1291(17.47)$ & & \\
\hline 11 & 2115 (13.27) & 1127 (13.19) & 988 (13.37) & & \\
\hline Weight (g) & $32.94 \pm 9.87$ & $34.02 \pm 0.36$ & $31.68 \pm 9.11$ & 15.18 & $<0.001$ \\
\hline Height $(\mathrm{cm})$ & $136.56 \pm 10.52$ & $136.78 \pm 10.18$ & $136.31 \pm 10.90$ & 2.76 & 0.006 \\
\hline WC (cm) & $59.64 \pm 9.37$ & $62.24 \pm 10.26$ & $56.63 \pm 7.13$ & 40.50 & $<0.001$ \\
\hline $\mathrm{BMI}\left(\mathrm{kg} / \mathrm{m}^{2}\right)$ & $17.33 \pm 3.22$ & $17.84 \pm 3.44$ & $16.74 \pm 2.83$ & 22.08 & $<0.001$ \\
\hline WHtR & $0.44 \pm 0.05$ & $0.45 \pm 0.06$ & $0.42 \pm 0.04$ & 48.69 & $<0.001$ \\
\hline General obesity category $^{\dagger}$ & & & & 731.88 & $<0.001$ \\
\hline Severe thinness & $60(0.38)$ & $37(0.43)$ & $23(0.31)$ & & \\
\hline Thinness & $420(2.64)$ & $183(2.14)$ & $237(3.21)$ & & \\
\hline Normal & $10681(67.02)$ & $5098(59.65)$ & $5583(75.54)$ & & \\
\hline Overweight & $2770(17.38)$ & $1638(19.17)$ & $1132(15.32)$ & & \\
\hline Obesity & $2006(12.59)$ & $1590(18.61)$ & $416(5.63)$ & & \\
\hline Central obesity category ${ }^{\ddagger}$ & & & & 569.44 & $<0.001$ \\
\hline Normal & $12515(78.56)$ & $6096(71.35)$ & $6419(86.91)$ & & \\
\hline Central obesity & 3415 (21.44) & $2448(28.65)$ & 967 (13.09) & & \\
\hline Puberty ${ }^{\S}$ & & & & 640.46 & $<0.001$ \\
\hline Normal & $5658(90.47)$ & 4094 (96.99) & 1564 (76.93) & & \\
\hline Precocious & 596 (9.53) & $127(3.01)$ & 469 (23.07) & & \\
\hline
\end{tabular}

*p for $t$ test or $\chi^{2}$ test.

†Defined as severe thinness (BMI for age $<-3 \mathrm{SD}$ ); thinness ( $-3 \mathrm{SD} \leq \mathrm{BMI}$ for age $<-2 \mathrm{SD})$; normal $(-2 \mathrm{SD} \leq \mathrm{BMI}$ for age $\leq 1 \mathrm{SD})$; overweight ( $1 \mathrm{SD}<\mathrm{BMl}$ for age $\leq 2 \mathrm{SD}$ ); obesity (BMl for age $>2 \mathrm{SD}$ ).

‡Defined as central obesity (WHtR $\geq 0.48$ in boys or WHtR $\geq 0.46$ in girls); normal (WHtR $<0.48$ in boys or WHtR $<0.46$ in girls).

$\S$ Defined as under 8 years for Tanner stage 2 or above for breast or pubic hair development and 10 years for menstruation in girls, and under 9 years for Tanner stage 2 or above for pubic hair or testicle development in boys.

$\mathrm{BMI}$, body mass index; WC, waist circumference; WHtR, waist to height ratio.

All figures are expressed as frequency (\%), all quantitative data are expressed as mean \pm SD.

Table 2 Associations between different types of obesity and the risk of precocious puberty

\begin{tabular}{|c|c|c|c|c|c|c|}
\hline \multirow[b]{2}{*}{ Puberty } & \multicolumn{3}{|l|}{ General obesity } & \multicolumn{3}{|l|}{ Central obesity } \\
\hline & Normal, N(\%) & Obesity, N(\%) & OR (95\% Cl) & Normal, N(\%) & Obesity, N(\%) & OR $(95 \% \mathrm{Cl})$ \\
\hline \multicolumn{7}{|l|}{ Boys } \\
\hline Precocious & 64 (50.39) & $33(25.98)$ & $\begin{array}{l}2.15 \text { (1.31 to } \\
3.50)\end{array}$ & 78 (23.01) & 49 (38.58) & $\begin{array}{l}2.10(1.46 \text { to } \\
3.03)\end{array}$ \\
\hline Precocious & 264 (56.29) & $65(13.86)$ & $\begin{array}{l}9.00(5.60 \text { to } \\
14.46)\end{array}$ & 331 (70.58) & $138(29.42)$ & $\begin{array}{l}5.40 \text { (4.10 to } \\
7.12)\end{array}$ \\
\hline
\end{tabular}


Table 3 Median age $(95 \% \mathrm{Cl})$ of attainment of different pubertal stages according to probit analysis in Shanghai children

\begin{tabular}{lllll} 
General obesity category & Girls & \multicolumn{3}{l}{ Boys } \\
\hline & $\mathbf{B}_{2}$ & $\mathbf{P H}_{2}$ & $\mathbf{P H}_{2}$ & $\mathbf{T}_{2}$ \\
\hline Severe thinness & $10.86(9.77-12.08)$ & $12.56(10.64-14.86)$ & $13.56(11.31-16.40)$ & $11.72(8.35-16.59)$ \\
Thinness & $9.88(9.58-10.18)$ & $11.13(10.69-11.60)$ & $14.50(13.00-16.34)$ & $11.28(9.74-13.15)$ \\
Normal weight & $8.85(8.79-8.91)$ & $10.73(10.62-10.84)$ & $13.96(13.46-14.60)$ & $10.57(10.31-10.88)$ \\
Overweight & $7.68(7.55-7.80)$ & $10.22(10.04-10.40)$ & $13.82(13.28-14.49)$ & $10.32(9.93-10.74)$ \\
Obesity & $7.14(6.93-7.35)$ & $10.18(9.89-10.48)$ & $13.66(13.13-14.32)$ & $10.27(9.87-10.70)$ \\
Total & $8.62(8.57-8.67)$ & $10.62(10.53-10.71)$ & $13.84(13.40-14.40)$ & $10.46(10.21-10.78)$ \\
\hline
\end{tabular}

$\mathrm{B}_{2}$, Tanner stage 2 for breast development; $\mathrm{PH}_{2}$, Tanner stage 2 for pubic hair development; $\mathrm{T}_{2}$, Tanner stage 2 for testicle development with testicular volume $\geq 4 \mathrm{~mL}$.

$\mathrm{CI}=6.97$ to 7.44 ) and 10.60 (95\% $\mathrm{CI}=10.26$ to 10.96 ) years for those with central obesity. The median age of $\mathbf{B}_{2}$ was slightly lower than that of $\mathrm{PH}_{2}$ in the central obesity group. For boys, the median ages of $\mathrm{PH}_{2}$ and $\mathrm{T}_{2}$ were $13.78(95 \%$ $\mathrm{CI}=13.34$ to 14.35$)$ and $10.52(95 \% \mathrm{CI}=10.28$ to 10.80$)$ years for those with non-central obesity, and $14.00(95 \%$ $\mathrm{CI}=13.47$ to 14.65$)$ and $10.33(95 \% \mathrm{CI}=9.95$ to 10.74$)$ years for those with central obesity. The median age of $\mathrm{T}_{2}$ was slightly lower and that of $\mathrm{PH}_{2}$ was a little higher in boys with central obesity than in those with non-central obesity.

\section{Relationship between WHtR, BMI Z-score and sexual} maturation

Using linear regression analysis, we analysed the relationship between WHtR, BMI Z-score and sexual maturation (table 4). The age of physical examination was estimated as the time of pubertal onset. For girls, both WHtR and BMI were negatively and statistically significantly related to the age of $\mathrm{B}_{2}$ and $\mathrm{PH}_{2}$. Higher WHtR was correlated with the earlier age of breast and pubic hair development; a similar change was observed in BMI Z-score. For boys, both WHtR and BMI were positively related to the age of $\mathrm{PH}_{2}$ but negatively associated with $\mathrm{T}_{2}$. However, statistical significance only existed in the correlation between BMI Z-score and age of $\mathrm{T}_{2}$. In addition, WHtR had greater impact on the age of $\mathrm{PH}_{2}$ while BMI Z-score had more influence on the age of $\mathrm{T}_{2}$.

\section{DISCUSSION}

This is a large-scale population-based cross-sectional survey of pubertal growth and development in children in Shanghai, China. The total detection rate of precocious puberty was $9.53 \%$ (3.01\% for boys, $23.07 \%$ for girls) in the present study.

Increasing evidence suggests that obesity is closely relevant to early sexual development in girls. ${ }^{7921-24}$ Atay $e t a l^{23}$ found a strong association between different levels of BMI SD scores and the occurrence of premature thelarche but not with premature pubarche among 4-8-year-old girls in Istanbul. Kaplowitz et $a l^{22}$ observed that greater BMI is associated with an increased likelihood of early appearance of pubic hair and breast development in American

Table 4 The relationship between age of Tanner 2 and WHtR and BMI by linear regression

\begin{tabular}{|c|c|c|c|c|c|c|}
\hline Index & $\mathbf{N}$ & Coefficient $\mathrm{B}_{0}(95 \% \mathrm{Cl})$ & SE & $\begin{array}{l}\text { Standardised } \\
\text { coefficients } B_{1}\end{array}$ & $\mathbf{t}$ & $\mathbf{p}$ \\
\hline \multicolumn{7}{|l|}{$B_{2}$ for girls } \\
\hline WHtR & 2256 & $-8.89(-9.97$ to 7.80$)$ & 0.55 & -0.32 & -16.06 & $<0.001$ \\
\hline BMI Z-score & 2258 & $-0.44(-0.48$ to 0.39$)$ & 0.02 & -0.37 & -18.81 & $<0.001$ \\
\hline \multicolumn{7}{|l|}{$\mathrm{PH}_{2}$ for girls } \\
\hline WHtR & 1093 & $-1.90(-3.41$ to 0.40$)$ & 0.77 & -0.08 & -2.49 & 0.013 \\
\hline BMI Z-score & 1093 & $-0.14(-0.20$ to 0.07$)$ & 0.03 & -0.12 & -4.16 & $<0.001$ \\
\hline \multicolumn{7}{|l|}{$\mathrm{PH}_{2}$ for boys } \\
\hline WHtR & 356 & $0.65(-1.25$ to 2.55$)$ & 0.96 & 0.04 & 0.67 & 0.501 \\
\hline BMI Z-score & 356 & $0.02(-0.10$ to 0.13$)$ & 0.06 & 0.01 & 0.26 & 0.795 \\
\hline \multicolumn{7}{|l|}{$T_{2}$ for boys } \\
\hline WHtR & 708 & $-0.65(-1.77$ to 0.46$)$ & 0.57 & -0.04 & -1.15 & 0.251 \\
\hline BMI Z-score & 708 & $-0.13(-0.20$ to 0.06$)$ & 0.03 & -0.14 & -3.75 & $<0.001$ \\
\hline
\end{tabular}

$\mathrm{B}_{2}$, Tanner stage 2 for breast development; $\mathrm{PH}_{2}$, Tanner stage 2 for pubic hair development; $\mathrm{T}_{2}$, Tanner stage 2 for testicle development with testicular volume $\geq 4$. 
girls aged 3-12 years. In addition, Rosenfield et $a l^{24}$ reported that girls with excessive BMI had a significantly higher prevalence of thelarche from ages 8.0 to 9.6 years and pubarche from ages 8.0 to 10.2 years. Our results are consistent with most studies in that obesity was a significant risk factor for precocious puberty. We observed that the median age of both thelarche and pubarche decreased with an increase in BMI. The estimated age of $\mathrm{B}_{2}$ and $\mathrm{PH}_{2}$ were also negatively related to $\mathrm{BMI}$ Z-score.

In boys, there are limited studies that have evaluated the association between early sexual maturation and obesity. Wang ${ }^{21}$ reported that early sexual maturation was negatively associated with overweight and obesity in boys aged 8-14 years in the United States in 1988-1994. In this population-based cross-sectional study, the prevalence of overweight was $23 \%$ and obesity $7 \%$ for boys with precocious puberty. The subjects were mainly non-Hispanic white $(25 \%)$, non-Hispanic black (36\%) and Mexican American (35\%). Additionally, Sorensen et $a l^{25}$ reported in a combined cross-sectional and longitudinal study in Denmark that BMI was negatively associated with testicular growth and pubic hair development, indicating that higher BMI results in a later age for pubertal onset in Caucasian boys aged 5.8-19.8 years. However, in a longitudinal population-based study, Lee $e t a l^{26}$ provided further evidence that higher BMI during early childhood is not associated with earlier pubertal onset in American boys. These boys were aged 211.5 years and their ethnicities were white $(79.5 \%)$ and non-white $(20.5 \%)$; and $12.2 \%$ of the boys were prepubertal at age 11.5 years according to Tanner genitalia staging. In contrast to these studies, Lee $e t$ $a l^{27}$ conducted a hospital-based gonadotropin-releasing hormone $(\mathrm{GnRH})$ stimulation test involving Korean boys with a mean age of 8.7 years and reported that excess adiposity may influence the hypothalamic-pituitarygonadal axis in boys, suggesting that boys who are obese enter puberty at an earlier age than normal weight boys. Dai et $a t^{28}$ described in a Chinese cross-sectional study that early sexual maturation was positively associated with obesity in boys only by the indicator of testicular volume. Our study was consistent with the positive results and further provided evidence of the relation between pubic hair development and obesity. The discrepancy of these findings might be explained by ethnic background differences, variation in the assessment criteria of pubertal stage and obesity, sample size, time factor, social culture, etc. The characteristics of our study and other related literature can be found in online supplementary table 1 . Our study also provided further evidence of the relation between pubic hair, testicular development and obesity. The timing of testicular development was decreased with increasing BMI and negatively related to BMI Z-score. For pubic hair, the median age of $\mathrm{PH}_{2}$ was slightly decreased with increased BMI, but the youngest age demonstrated a wide range of $95 \%$ CIs in the severe thinness group and might be related to the small sample size. Though the estimated age of $\mathrm{T}_{2}$ was positively related to BMI Z-score, it showed no statistical significance. The results for pubic hair development were inconsistent; one possible reason might be that the analysis of BMI Z-score excluded boys with $\mathrm{T}_{3}$ or greater Tanner stage who were more likely to be obese. Obesity had little or no effect on pubic hair development; it mainly influenced testicle development.

More and more researchers have explored the linkage between precocious puberty and obesity, but the potential mechanisms remain unclear. Longitudinal epidemiological evidence suggests that obesity has an important effect on precocious puberty. ${ }^{921}{ }^{27}$ The effect of obesity is likely to be related to leptin, a hormone secreted by adipocytes, which affect pubertal onset through activation of permissive hypothalamic GnRH secreting neurons. ${ }^{29}$ As a consequence of obesity, insulin resistance plays an important role in the timing of puberty by interfering with leptin signalling and causing additional weight gain. ${ }^{29}$ Additionally, premature adrenarche is reported to be associated with obesity, but the potential mechanisms remain unknown. ${ }^{30}$

Research is lacking on the effect of fat distribution on pubertal development based on a large representative population. Biro et $a l^{30}$ suggested both the adrenarche pathway for pubic hair development and the thelarche pathway for breast development were influenced by body fat and BMI. Even though there is an overlap between central obesity and obesity defined by BMI, BMI measurement is not effective for providing information on fat distribution. WHtR, which is calculated using WC and height, is reported to easily influence fat distribution and is less affected by gender and ethnicity compared with BMI. ${ }^{31}$ David et al ${ }^{1}$ emphasised the importance of obtaining information on fat distribution and, particularly, WC in children. They found that a relative excess of adipose tissue in the abdominal or central region was related to adverse concentrations of insulin, which was independent of weight and height. Our study further clearly revealed a relatively higher rate of precocious puberty and earlier median age of thelarche and testicular development rather than pubarche in children with central obesity. Furthermore, we revealed an earlier median age of thelarche and pubarche development among girls with central obesity. Also, higher WHtR was correlated to earlier age of estimated timing of $\mathrm{B}_{2}$ and $\mathrm{PH}_{2}$, but the influence of WHtR was weaker than BMI. For boys, central obesity varied the effect. The timing of testicular development was earlier in boys with central obesity; WHtR affected the timing of testicular development more than BMI, but pubarche development demonstrated a totally opposite outcome. That is, the timing was later in boys with central obesity and positively related to WHtR. But BMI had a greater influence than WHtR. These findings hinted that the different effects of WHtR on sex development were shown to different extents and with different mechanisms.

\section{Strengths and limitations of this study}

This study is a large population-based cross-sectional study and the subjects were representative of the general 
population for Shanghai. Early pubertal development was found to be associated with obesity and central obesity, which is of relevance to the current public health concern about the risk factors associated with the timing of puberty. However, some limitations should be acknowledged. First, though the sample size is large, the results cannot determine the causality or the speed of the consecutive pubertal stages because sexual development and obesity are measured at the same time point. In addition, our cross-sectional study could not measure the timing of pubertal onset exactly. Therefore, longitudinal investigations are needed to more accurately evaluate timing of pubertal onset and determine the causal direction, that is whether obesity has an impact on precocious puberty during childhood.

Second, we were unable to characterise the parents' pubertal development, especially a history of precocious puberty, which may influence the pubertal development of the next generation. Since precocious puberty was idiopathic, we will take parents' pubertal information into consideration in the follow-up study.

Third, it would be desirable if a more accurate assessment of breast development were available in children who are overweight or obese. Discriminating between glandular breast and fat tissue is a critical concern, and inspection or palpation may lead to errors in estimating precocious puberty in children who are obese with excessive subcutaneous fat in the chest. It was rather difficult to employ imaging diagnosis on a large scale in children taking part in the physical examination, so we only adopted inspection combined with palpation, which is the method often used in population epidemiological studies: Rosenfield $e t a l^{24}$ used inspection to ascertain pubertal signs of the breast in 8-18-year-old children in the Third National Health and Nutrition Examination Survey (NHANES III). A cohort study of breast development sponsored by the National Institute of Environmental Health Sciences/ National Cancer Institute Breast Cancer and the Environment Research programme (BCERP) indicated that breast development was assessed through both observation and palpation, which limited misclassification of fat tissue deposited in the chest area. ${ }^{32}$ Bias may exist in distinguishing testicular development from hydrocele or cysts, etc. We did not assess bone age because it was difficult to apply X-ray detection in a large-scale population-based study. We will apply bone age diagnosis and improve the research methods using imaging diagnosis, such as B-ultrasonic scan, in our further study.

\section{CONCLUSIONS}

Early pubertal development was found to be positively associated with obesity and central obesity. We observed that the pubertal timing of breast and pubic hair decreased with BMI as WHtR increased in girls, and testicular volume decreased but pubic hair increased as BMI and WHtR increased in boys. We also found earlier median age of thelarche and testicular development rather than pubarche in children with central obesity. Children with obesity are more vulnerable to psychological problems beyond physical influence while early puberty undoubtedly strengthens these problems. Further, children with obesity may need special attention regarding puberty knowledge and mental health in school education. We hope our findings will serve as a reference for future research investigating the mechanisms and causal effects of precocious puberty and obesity, leading to the development of approaches to analysing precocious puberty in clinical settings.

Author affiliations

${ }^{1}$ School of Public Health, Shanghai Jiao Tong University, Shanghai, China ${ }^{2}$ Pediatric Translational Medicine Institute, Shanghai Children's Medical Center Affiliated to Shanghai Jiaotong University School of Medicine, Shanghai, China ${ }^{3}$ Child Health Advocacy Institute, Shanghai Children's Medical Center Affiliated to Shanghai Jiaotong University School of Medicine, Shanghai, China

${ }^{4}$ Shanghai Key Laboratory of Children's Environmental Health, Shanghai Jiaotong University School of Medicine Xinhua Hospital, Shanghai, China

${ }^{5}$ Department of Developmental and Behavioral Pediatrics, Shanghai Children's Medical Center Affiliated to Shanghai Jiaotong University School of Medicine, Shanghai, China

${ }^{6}$ Department of Endocrine and Genetic Metabolic Diseases, Shanghai Children's Medical Center Affiliated to Shanghai Jiaotong University School of Medicine, Shanghai, China

Contributors FJ and YZ designed the research; YZ, WS, YC, YJ, YS, QL, LZ, QZ performed the study; CC and SL drafted the manuscript and performed statistical analyses; SL and XW contributed to interpretation of the results and critically reviewed the manuscript.

Funding This work was supported by Chinese National Natural Science Foundation [81172685, 81602868, 81601162, 81602870]; MOE New Century Excellent Talents [NCETA13A0362]; Shanghai Science and Technology Commission [14441904004]; The fourth round of ThreeAYear Public Health Action Plan (2015A2017) [GWIVA36] ;Shanghai Municipal Education Commission [D1502].

Competing interests None declared.

Ethics approval The Institutional Review Boards of the Shanghai Childrens Medical Center.

Provenance and peer review Not commissioned; externally peer reviewed. Data sharing statement No additional data are available.

Open Access This is an Open Access article distributed in accordance with the Creative Commons Attribution Non Commercial (CC BY-NC 4.0) license, which permits others to distribute, remix, adapt, build upon this work non-commercially, and license their derivative works on different terms, provided the original work is properly cited and the use is non-commercial. See: http://creativecommons.org/ licenses/by-nc/4.0/

Correction notice This article has been corrected since it first published. The Correspondence section has been updated to include both Corresponding authors.

(c) Article author(s) (or their employer(s) unless otherwise stated in the text of the article) 2017. All rights reserved. No commercial use is permitted unless otherwise expressly granted.

\section{REFERENCES}

1. Clarkson J, Han SK, Liu X, et al. Neurobiological mechanisms underlying kisspeptin activation of gonadotropin-releasing hormone (GnRH) neurons at puberty. Mol Cell Endocrinol 2010;324:45-50.

2. Ma HM, Du ML, Luo XP, et al; Pubertal Study Group of the Society of Pediatric Endocrinology and Genetic Disease, Chinese Medical Association. Onset of breast and pubic hair development and menses in urban Chinese girls. Pediatrics 2009;124:e269-77.

3. Jaruratanasirikul S, Chanpong A, Tassanakijpanich N, et al. Declining age of puberty of school girls in southern Thailand. World $J$ Pediatr 2014;10:256-61. 
4. Rubin C, Maisonet M, Kieszak S, et al. Timing of maturation and predictors of menarche in girls enrolled in a contemporary British cohort. Paediatr Perinat Epidemiol 2009;23:492-504.

5. Golub MS, Collman GW, Foster PM, et al. Public health implications of altered puberty timing. Pediatrics 2008;121(Suppl 3):S218-S230.

6. Adair LS, Gordon-Larsen P. Maturational timing and overweight prevalence in US adolescent girls. Am J Public Health 2001;91:642-4.

7. Bratberg GH, Nilsen $\mathrm{TI}$, Holmen TL, et al. Early sexual maturation, central adiposity and subsequent overweight in late adolescence. A four-year follow-up of 1605 adolescent Norwegian boys and girls: the Young HUNT study. BMC Public Health 2007;7:54.

8. van Lenthe FJ, Kemper HC, van Mechelen W, et al. Biological maturation and the distribution of subcutaneous fat from adolescence into adulthood: the Amsterdam growth and health study. Int J Obes Relat Metab Disord 1996;20:121-9.

9. Davison KK, Susman EJ, Birch LL. Percent body fat at age 5 predicts earlier pubertal development among girls at age 9 . Pediatrics 2003;111:815-21.

10. Burt Solorzano CM, McCartney CR. Obesity and the pubertal transition in girls and boys. Reproduction 2010;140:399-410.

11. Freedman DS, Serdula MK, Srinivasan SR, et al. Relation of circumferences and skinfold thicknesses to lipid and insulin concentrations in children and adolescents: the Bogalusa heart study. Am J Clin Nutr 1999;69:308-17.

12. Tanita M, Matsunaga J, Miyamura $Y$, et al. Polymorphic sequences of the tyrosinase gene: allele analysis on 16 OCA1 patients in Japan indicate that three polymorphic sequences in the tyrosinase gene promoter could be powerful markers for indirect gene diagnosis. $J$ Hum Genet 2002;47:1-6.

13. Marshall WA, Tanner JM. Variations in pattern of pubertal changes in girls. Arch Dis Child 1969;44:291-303.

14. Marshall WA, Tanner JM. Variations in the pattern of pubertal changes in boys. Arch Dis Child 1970;45:13-23.

15. Bridges NA, Christopher JA, Hindmarsh PC, et al. Sexual precocity: sex incidence and aetiology. Arch Dis Child 1994;70:116-8.

16. Lebrethon MC, Bourguignon JP. Management of central isosexual precocity: diagnosis, treatment, outcome. Curr Opin Pediatr 2000;12:394-9.

17. Klein KO. Precocious puberty: who has it? who should be treated? $J$ Clin Endocrinol Metab 1999;84:411-4.

18. de Onis M, Onyango AW, Borghi E, et al. Development of a WHO growth reference for school-aged children and adolescents. Bull World Health Organ 2007;85:660-7.
19. de Onis M, Lobstein T. Defining obesity risk status in the general childhood population: which cut-offs should we use? Int J Pediatr Obes 2010;5:458-60.

20. Subspecialty Group of Endocrinologic, Hereditary and Metabolic Diseases, The Society of Pediatrics, Chinese Medical Association, Subspecialty Group of Cardiology, The Society of Pediatrics, Chinese Medical Association, Subspecialty Groups of Child Health Care, The Society of Pediatrics, Chinese Medical Association. [The definition of metabolic syndrome and prophylaxis and treatment proposal in Chinese children and adolescents]. Zhonghua Er Ke Za Zhi 2012;50:420-2.

21. Wang $\mathrm{Y}$. Is obesity associated with early sexual maturation? A comparison of the association in American boys versus girls. Pediatrics 2002;110:903-10.

22. Kaplowitz PB, Slora EJ, Wasserman RC, et al. Earlier onset of puberty in girls: relation to increased body mass index and race. Pediatrics 2001;108:347-53.

23. Atay Z, Turan S, Guran T, et al. The prevalence and risk factors of premature thelarche and pubarche in 4- to 8-year-old girls. Acta Paediatr 2012;101:e71-e75.

24. Rosenfield RL, Lipton RB, Drum ML. Thelarche, pubarche, and menarche attainment in children with normal and elevated body mass index. Pediatrics 2009:123:84-8.

25. Sørensen K, Aksglaede L, Petersen JH, et al. Recent changes in pubertal timing in healthy Danish boys: associations with body mass index. J Clin Endocrinol Metab 2010;95:263-70.

26. Lee JM, Kaciroti N, Appugliese D, et al. Body mass index and timing of pubertal initiation in boys. Arch Pediatr Adolesc Med 2010;164:139-44.

27. Lee HS, Park HK, Ko JH, Jh K, et al. Impact of body mass index on luteinizing hormone secretion in gonadotropin-releasing hormone stimulation tests of boys experiencing precocious puberty. Neuroendocrinology 2013;97:225-31.

28. Dai YL, Fu JF, Liang L, et al. Association between obesity and sexual maturation in Chinese children: a muticenter study. Int $J$ Obes 2014;38:1312-6.

29. Roemmich JN, Rogol AD. Role of leptin during childhood growth and development. Endocrinol Metab Clin North Am 1999;28:749-64.

30. Biro FM, Lucky AW, Simbartl LA, et al. Pubertal maturation in girls and the relationship to anthropometric changes: pathways through puberty. J Pediatr 2003;142:643-7.

31. Daniels SR, Khoury PR, Morrison JA. Utility of different measures of body fat distribution in children and adolescents. Am J Epidemiol 2000;152:1179-84.

32. Biro FM, Greenspan LC, Galvez MP, et al. Onset of breast development in a longitudinal cohort. Pediatrics 2013;132:1019-27. 
Corrections: Investigating the relationship between

precocious puberty and obesity: a cross-sectional study in Shanghai, China

Chen C, Zhang Y, Sun W, et al. Investigating the relationship between precocious puberty and obesity: a cross-sectional study in Shanghai, China. BMJ Open 2017;7:e014004. doi: 10.1136/bmjopen-2016-014004

This article has been corrected since it first published. Both Liu Shijian and Jiang Fan are listed a corresponding authors for this paper.

Open Access This is an Open Access article distributed in accordance with the Creative Commons Attribution Non Commercial (CC BY-NC 4.0) license, which permits others to distribute, remix, adapt, build upon this work non-commercially, and license their derivative works on different terms, provided the original work is properly cited and the use is non-commercial. See: http://creativecommons.org/licenses/by-nc/4.0/

C Article author(s) (or their employer(s) unless otherwise stated in the text of the article) 2017. All rights reserved. No commercial use is permitted unless otherwise expressly granted.

BMJ Open 2017;7:e016427corr1. doi:10.1136/bmjopen-2016-014004corr1

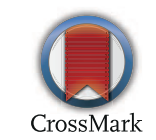

